\title{
The Relationship between College Students' Resilience and Career Decision-Making Difficulties: The Mediating Role of Career Adaptability
}

\author{
Liman Pang1, Xiu Wang1, Fan Liu', Tingting Fang ${ }^{2}$, Huaruo Chen ${ }^{1 *}$, Ya Wen ${ }^{3 *}$ \\ ${ }^{1}$ School of Education Science, Nanjing Normal University, Nanjing, China \\ ${ }^{2}$ School of Psychology, Nanjing Normal University, Nanjing, China \\ ${ }^{3}$ School of Teachers and Education, Nanjing Xiaozhuang University, Nanjing, China \\ Email: *190601021@njnu.edu.cn, *ywen1133@126.com
}

How to cite this paper: Pang, L. M., Wang, X., Liu, F., Fang, T. T., Chen, H. R., \& Wen, Y. (2021). The Relationship between College Students' Resilience and Career Decision-Making Difficulties: The Mediating Role of Career Adaptability. Psychology, 12, 872-886.

https://doi.org/10.4236/psych.2021.126053

Received: May 17, 2021

Accepted: June 18, 2021

Published: June 21, 2021

Copyright $\odot 2021$ by author(s) and Scientific Research Publishing Inc. This work is licensed under the Creative Commons Attribution International License (CC BY 4.0).

http://creativecommons.org/licenses/by/4.0/

\begin{abstract}
The arrival of the post-epidemic era has brought more uncertainties to college students' job search and employment. Therefore, it is necessary to help students how to make career choices in an uncertain environment. Based on the career adaptation model theory, this research proposes a relationship model of resilience, career adaptability, and career decision-making difficulties. Through a survey of 666 Chinese college students, it is found that resilience and career adaptability can reduce students' career decision-making difficulties. Career adaptability plays a mediating role between resilience and career decision-making difficulties. Finally, it points out the importance of paying attention to the positive factors of students in career decision-making and puts forward some suggestions.
\end{abstract}

\section{Keywords}

Resilience, Career Decision-Making Difficulties, Career Adaptability, Life Design Paradigm

\section{Introduction}

According to statistics from the Ministry of Education of China, there will be 8.74 million college graduates in China in 2020. Affected by multiple factors such as the new crown pneumonia epidemic and economic downward pressure, the employment situation of college graduates is not optimistic. Faced with these unexpected changes, individuals need to have several abilities to adapt to the 
complex and changeable external environment and enhance their employment competitiveness. In such a job search process with various uncertain factors, the ability required to cope with various changes not only includes some objective factors and basic knowledge and skills but also requires individuals to have some abilities and qualities with their unique advantages, such as resilience, career adaptability (Tugade \& Fredrickson, 2004; Savickas et al., 2009). Resilient people are usually optimistic about life, have high life energy, are open to new experiences and curiosity, and have an internal control center (Tugade \& Fredrickson, 2004). (Semmer, 2006) also put forward a similar view, that individuals with high resilience are optimistic about the world, and difficult and stressful situations are usually seen as challenges and new experiences. Studies have shown that resilience is related to the individual's successful response to the challenges in the career decision-making process. Individuals with higher resilience levels show lower levels of career decision-making difficulties in the career decisionmaking process. Therefore, resilience as a positive advantage ability can predict an individual's career decision-making level.

The life design (LD) paradigm is mainly to help individuals construct their own professional lives in the modern and ever-changing society, and is a career consulting paradigm based on social constructivist epistemology (Savickas et al., 2009). In the life design paradigm, resilience is considered by career consultants to be an indispensable resource for coping with career development tasks and changing work and career conditions. As the core concept of the life design paradigm, career adaptability also plays a key role in the life design (LD) paradigm (Wehmeyer et al., 2018), which is a basic resource to help individuals plan for an uncertain future, face adverse conditions, and adapt to changes in living conditions (Xu et al., 2020). In addition, career adaptability can help individuals have the necessary social resources to cope with career development tasks, career transitions, and work trauma (Savickas et al., 2009). Studies have found that career adaptability is related to an individual's career planning, career exploration, career self-efficacy, and career decision-making self-efficacy (Rudolph et al., 2017; Parmentier et al., 2021). Therefore, this study will explore the impact of two important personal resources, resilience and career adaptability, on career decision-making difficulties. And confirm the relationship between resilience, career adaptability, and career decision-making difficulties.

\section{Theoretical Background}

\subsection{Resilience}

Resilience is a personal quality that helps individuals thrive in adversity, and it can be regarded as an individual's ability to successfully cope with stress (Connor \& Davidson, 2003). The earliest measure of resilience is the Resilience Scale (RS) compiled by (Wagnild \& Young, 1993) for the elderly. The scale includes two dimensions of personal ability and acceptance of self and life. Among them, personal ability includes independence and self-confidence, determination, sense 
of control, persistence. But the scale mainly measures the elderly with psychological problems, and the scope of application is relatively small. In 2003, Connor and Davidson compiled the Connor-Davidson Resilience Scale (CD-RISC), which includes five dimensions: ability, instinct, acceptance of change, control, and mental influence (Connor \& Davidson, 2003). The scale has been revised locally in China, and it applies to a wide range of objects (Yu et al., 2007).

In recent years, resilience has attracted the attention of researchers in the field of career consulting. Life Design (LD) is a paradigm of career counseling, and its value lies in helping individuals cope with major changes and turning challenges into opportunities (Maree, 2017). The Life Design (LD) paradigm can not only improve the individual's career adaptability but also increase their career resilience in a professional context that is no longer a "control" environment. It is an important strategy that enables people to express meaning and find a sense of purpose in their careers (Maree \& Symington, 2015; Maree \& Pollard, 2009). In the life design paradigm, resilience is regarded as the psychological capital of positive personality. Studies have shown that resilience has a certain relationship with career adaptability. (Bimrose \& Hearne, 2012) used qualitative research methods to study mid-career adults and workplace professionals. The study found that resilience and career adaptability are mutually reinforcing. Together, they provide an explanatory framework for helping adults seeking career counseling support to understand their situation and consider how they can advance constructively in their career development.

\subsection{Career Decision-Making Difficulties}

Career decision-making difficulties are defined as various difficulties encountered by individuals in the career decision-making process (Gati, Krausz, \& Osipow, 1996). (Gati et al., 1996) developed a career decision-making difficulty model based on "ideal career decision-maker" model, which is divided into three categories of difficulties. They are "lack of preparation" before making specific career decisions, "lack of information" and "inconsistent information" in the actual process of career decisions. These three difficulties can be further divided into 10 specific categories. Later, they constructed the Career Decision-Making Difficulty Questionnaire (CDDQ) based on decision-making theory and classification of career decision-making difficulties. At present, the questionnaire has been verified locally by scholars in many countries (such as China, South Korea, Turkey, Croatia, etc.). Multiple empirical studies have shown that CDDQ is a reliable and effective method for measuring the performance of individual career decision-making difficulties (Gati et al., 2000; Tien, 2005; Levin et al., 2019).

Previous studies have mainly explored the relevant influencing factors of career decision-making difficulties, as well as the verification of the career decisionmaking difficulties scale and the study of differences in cross-cultural groups (Zhou \& Santos, 2007). In terms of influencing factors, it mainly examines the relationship between career decision-making difficulties and individual emo- 
tions and personality. For example, some scholars have studied the influence of personality traits on career decision-making difficulties (Fabio et al., 2012; Fabio et al., 2014). Research has found that neuroticism in personality traits is related to lack of information in career decision-making difficulties. In addition, more and more studies have explored the impact of positive factors on career decision-making difficulties, including resilience, career adaptability, and psychological capital (Rudolph et al., 2017; Shin \& Kelly, 2015). Studies have confirmed that resilience has a certain influence on individual career decisionmaking. (Shin \& Kelly, 2015) explored the predictive effect of resilience on career decision-making difficulties. The research results show that resilience is inversely proportional to the overall level of career decision-making, and resilience has different effects on difficulties encountered before and during decisionmaking. Although resilience has a smaller impact on career preparation, it has a greater negative impact on lack of information and inconsistent information. Overall, problem-solving actions related to resilience seem to help reduce or resolve difficulties caused by lack of or inconsistent information (Shin \& Kelly, 2015).

\subsection{The Mediating Role of Career Adaptability}

Career adaptability originated from the core concept of Super's career development theory, namely career maturity. (Super et al., 1981) updated and revised this theory and proposed the concept of "career adaptability" (Super \& Knasel, 1981). Later, Savickas has further enriched and improved the theoretical construction of career adaptability based on Super (Savickas, 1997). Based on this, (Savickas, 1997) proposed and gradually established a career construction theory from the perspectives of individual constructivism, social constructivism, and postmodernism. Savickas further revised and improved the theoretical construction of career adaptability in 2005, and proposed a more complete construction model. He believes that the development of individual career adaptability develops along its four dimensions or stages, which are career concern, career control, career curiosity, and career confidence (Savickas, 2005). (Savickas et al., 2012) developed a four-dimensional structure of the "Career Adaptability Scale" (CAAS) based on this theoretical model. The scale has been tested in 13 countries and regions including Europe, America, Japan, and China, and has passed the consistency test under different cultural backgrounds. Therefore, the scale has high applicability (Maggiori, Rossier, \& Savickas, 2015).

The research on career adaptability mainly focuses on the relationship between the predictors of career adaptability and the results of adaptation. Studies have shown that career adaptability as a positive personal-psychological resource is related to a series of positive adaptation responses and adaptation results. Including higher professional decision-making self-efficacy, more positive decision-making results, life satisfaction and so on (Chui et al., 2020; Ginevra et al., 2017; Rudolph et al., 2017). (Hirschi et al., 2015) used binary correlation me- 
thods in their research to evaluate the relationship between career adaptability and adaptation results (including career decision-making difficulties, career planning, etc.), and confirmed that there is a correlation between career adaptability and career decision-making difficulties. At the same time, in a further test of the mediating effect, they found that a higher level of attention in the four dimensions of career adaptability (attention, control, curiosity, and confidence) predicts fewer career decision-making difficulties in the future, and the control dimension negatively predicts individual career decision-making difficulties. In addition, some researchers have confirmed the relationship between the two variables, (Karacan-Ozdemir, 2019) conducted research on the career adaptability and career decision-making difficulties of Turkish high school students and confirmed that the higher the level of career adaptability, the lower the level of career decision-making difficulty. (Rudolph et al., 2017) used a meta-analysis method to study career adaptability, indicating that career adaptability plays a mediating role between adaptive ability and adaptive response (including career decision-making difficulties). This on the other hand confirms the relationship between career adaptability and career decision-making difficulties. Some researchers also pointed out that in the adaptive career construction model, adaptive ability refers to an individual's adaptability, which can mobilize the individual's adaptive resources (career adaptability) to form an adaptive response to produce an adaptive result. This theoretical model has been confirmed by many scholars (Hirschi et al., 2015; Rudolph et al., 2017; Savickas et al., 2018; Jia et al., 2020). (Jia et al., 2020) used this theoretical framework to study the relationship between individual personality factors (adaptive ability), career adaptability (adaptive resources), and career decision-making difficulties (adaptive response). The results show that career adaptability plays a mediating role in individual personality factors and career decision-making difficulties. Therefore, according to the sequence of adaptation models, this study believes that career adaptability, as an adaptation resource, plays a mediating role in career adaptability and career decision-making difficulties. This research proposes the following hypotheses:

Hypothesis 1: Resilience is negatively correlated with career decision-making difficulties;

Hypothesis 2: Career adaptability is negatively correlated with career decision-making difficulties;

Hypothesis 3: Career adaptability plays a mediating role between resilience and career decision-making difficulties (Figure 1).

\subsection{Research Goal}

In the existing studies, the research groups on the relationship between resilience and career adaptability are high school students, company employees, and parents. The relationship between resilience and career adaptability of college students is still unclear. In addition, there is less literature on resilience and career 


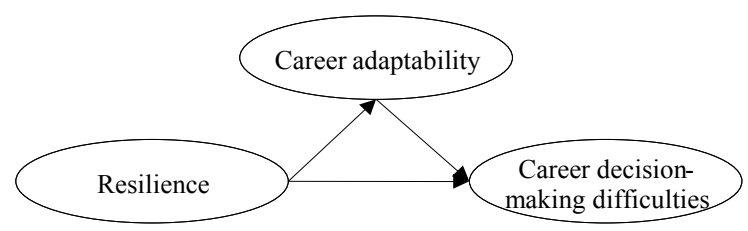

Figure 1. Mediating model diagram.

decision-making. Although foreign researchers have supplemented the research on resilience in the career field, under the Chinese background, the performance of career decision-making difficulties of students with different levels of resilience needs further research.

In view of the shortcomings of existing research, resilience and career adaptability are of great significance for individuals to cope with changes. Therefore, this study aims to analyze the relationship between Chinese college students' resilience, career adaptability, and career decision-making difficulties. This research proposes a model of the relationship between resilience, career adaptability and career decision-making difficulties, is based on the career adaptation theoretical model, and explores the influence mechanism of resilience in individual career fields. It is expected to provide a reference for follow-up research on resilience and career fields, and at the same time, it also provides a theoretical basis for reducing the difficulty of students' career decision-making, and provides some inspiration for students' early career development and practical applications in the field of career consulting.

\section{Methods}

\subsection{Participants}

This study randomly selected 666 college students from 6 provinces including Guangxi, Guangdong, Zhejiang, Jiangsu, Shanxi, and Tianjin, with an average age of 20.96 years (ranging from 17 to 25 years old, $S D=1.54$ ). Of the total sample, 186 were males (27.9\%), 480 females (72.1\%). Among the sample, 206 were freshmen, 159 were sophomores, 136 were juniors, and 165 were seniors. The sample of this research covers many types of universities, mainly including top universities (32.7\%), second-tier universities (23\%), and 3-year vocational colleges (44.3\%). In this sample, there are 513 students majoring in humanities and social sciences (77\%), and 153 students majoring in natural sciences (23\%). In this study, a total of 835 questionnaires were distributed and 835 were recovered. To ensure the validity of the data, blank questionnaires or questionnaires with uniform answers and questionnaires with an answer time of less than 120 seconds were excluded. A total of 666 valid questionnaires $(79.76 \%)$ were obtained.

\subsection{Measurement}

\subsubsection{Connor-Davidson Resilience Scale}

It is compiled by Connor-Davidson in 2003 and revised by Yu and Yang in 2007, 
which conforms to the Connor-Davidson Resilience Scale (CD-RISC) for Chinese college students. It consists of three dimensions, Tenacity, Strength, and Optimism. In addition, there are 25 items in total. Each item is scored on the 5 -point Likert-type scale $(1=$ never to $5=$ always $)$. The higher the score is, the stronger the resilience is. The typical item is "Past success gives me the confidence to face setbacks or challenges." In this study, the Cronbach coefficient of the scale was 0.946 .

\subsubsection{Career Adaptability Scale}

The Career Adapt-Abilities Scale (CAAS) was compiled and developed by (Savickas \& Porfeli, 2012) revised by Hou and her colleagues. The scale has 24 items and four dimensions, divided into career concern, career control, Career curiosity and career confidence. The scale is a self-reported 5-point Likert-type scale (Hou et al., 2012). In the present study, the Cronbach coefficient of the scale was 0.948 .

\subsubsection{Career Decision-Making Difficulty Scale}

This research uses the Career Decision-Making Difficulty Scale (CDDQ) compiled by Gati et al. revised by Li Na. The scale includes three sub-questions: lack of readiness (including lack of career planning, unreasonable beliefs, and indecision); lack of information (including four factors: insufficient self-information, insufficient occupational information, insufficient social-environmental information, and insufficient information acquisition channels); inconsistent information (including three factors: external conflict, internal conflict, and emotional discomfort). There are a total of 35 questions in the scale, with Likert's 5-point scoring, 1 is completely non-conforming, and 5 is completely conforming. The total score represents the level of the total career decision-making difficulty. In this study, the Cronbach coefficient of the scale was 0.947 .

\subsection{Data Analysis}

Use SPSS 24.0 to input data, and conduct reliability test, descriptive statistics, and correlation analysis. Then use AMOS24.0 to test the mediating model. The confirmatory factor analysis method was used to test the fit of the mediating model, and the Bias Corrected and Percentile method was used to test the mediating effect.

\section{Results}

\subsection{General Description}

The demographic statistics of the research sample are shown in Table 1. Participating in this sample survey, the only child of the family accounted for $25.2 \%$, and the non-only child of the family accounted for $74.8 \%$. Mothers' education is mainly at elementary school and below. Their fathers' education is the most common in junior high school. The monthly household income is less than 5000 yuan accounted for $58.3 \%, 5000-10,000$ yuan accounted for $28.8 \%$, and 10,000 
Table 1. Basic information of the sample.

\begin{tabular}{|c|c|c|c|}
\hline Variable & Category & Frequency & $\%$ \\
\hline \multirow{2}{*}{ one-child family } & yes & 168 & 25.2 \\
\hline & no & 498 & 74.8 \\
\hline \multirow{4}{*}{ Mother's degree } & elementary school and below & 269 & 40.4 \\
\hline & junior high school & 228 & 34.2 \\
\hline & high school & 84 & 12.6 \\
\hline & college degree and above & 85 & 12.8 \\
\hline \multirow{4}{*}{ Father's degree } & elementary school and below & 174 & 26.1 \\
\hline & junior high school & 270 & 40.5 \\
\hline & high school & 113 & 17 \\
\hline & college degree and above & 109 & 16.4 \\
\hline \multirow{3}{*}{ family monthly income } & 5000 and below & 388 & 58.3 \\
\hline & $5000-10,000$ & 192 & 28.8 \\
\hline & 10,000 and above & 86 & 12.9 \\
\hline \multirow{2}{*}{ home location } & city & 215 & 32.3 \\
\hline & rural & 451 & 67.7 \\
\hline \multirow{2}{*}{$\begin{array}{l}\text { have you participated in a club or- } \\
\text { ganization }\end{array}$} & yes & 529 & 79.4 \\
\hline & no & 137 & 20.6 \\
\hline \multirow{2}{*}{ have an internship or part-time job } & yes & 464 & 69.7 \\
\hline & no & 202 & 30.3 \\
\hline \multirow{2}{*}{ the nature of the school } & public & 532 & 79.9 \\
\hline & private & 134 & 20.1 \\
\hline
\end{tabular}

and above accounted for $12.9 \%$. In this sample, $32.3 \%$ of students live in cities and $67.7 \%$ in rural areas. Among them, $79.4 \%$ of students have participated in clubs and organizations, and $69.7 \%$ have had internships or part-time jobs. Among the surveyed subjects, $79.9 \%$ were in public schools and $20.1 \%$ were in private schools.

Table 2 shows the descriptive statistics of each variable. It can be seen from the table that the career adaptability of college students is at the upper-middle level, and the average values of each dimension are 3.664 (career concern), 3.845 (career control), 3.751 (career curiosity), 3.703 (career confidence). The resilience level of college students is at a moderately higher level. The average value of resilience is 3.376, strength is 3.564, and optimism is 3.37. College students' career decision-making difficulties are at a moderately lower level. The average value of the lack of readiness dimension is 2.811 , the average value of the lack of information dimension is 2.855 , and the average value of the inconsistent information dimension is 2.891 .

\subsection{Correlation Description}

In order to analyze whether there is a correlation between resilience, career 
Table 2. Descriptive statistics of each variable.

\begin{tabular}{rcccc}
\hline & Mean & SD & Min & Max \\
\hline career concern & 3.664 & 0.648 & 1.000 & 5.000 \\
career control & 3.845 & 0.614 & 1.000 & 5.000 \\
career curiosity & 3.751 & 0.621 & 1.000 & 5.000 \\
career confidence & 3.703 & 0.632 & 1.000 & 5.000 \\
tenacity & 3.376 & 0.629 & 1.150 & 5.000 \\
strength & 3.564 & 0.595 & 1.380 & 5.000 \\
optimism & 3.371 & 0.652 & 1.500 & 5.000 \\
lack of readiness & 2.811 & 0.656 & 1.000 & 4.330 \\
lack of information & 2.855 & 0.669 & 1.000 & 5.000 \\
inconsistent information & 2.891 & 0.674 & 1.000 & 4.820 \\
\hline
\end{tabular}

adaptability, and career decision-making difficulties, the study uses Pearson's product difference correlation analysis. The results found that there is a pairwise correlation between resilience, career adaptability, and career decision-making difficulties. There is a positive correlation between resilience and career adaptability (as shown in Table 3 ), and the correlation coefficient is $0.742(p<0.01)$. There is a negative correlation between decision-making difficulties, and the correlation coefficient is $-0.427(p<0.01)$. There is a negative correlation between career adaptability and career decision-making difficulties, and the correlation coefficient is $-0.450(p<0.01)$. Thus, Hypothesis 1 and Hypothesis 2 were supported.

\subsection{Test of the Mediating Path Model}

This study uses career adaptability as a mediating variable for resilience and career decision-making difficulties. Through the use of Amos24.0 for mediating path analysis, it is tested whether the measured mediating path model is consistent with the data, and several fitting indexes are also calculated to determine whether the structural model meets the sample data. All values obtained from the model fit index indicate that the model fits the data very well (as shown in Table 4). More specifically, $x^{2}=122.464, d f=32, x^{2} / d f=3.827$, goodness of fit index $(\mathrm{GFI})=0.965$, adjusted goodness of fit index $(\mathrm{AGFI})=0.941$, tucker-Lewis index $(\mathrm{TLI})=0.977$, comparative fit index $(\mathrm{CFI})=0.983$, and approximate root mean square error (RMSEA) is 0.065 , indicating that the model fits well.

\subsection{Analysis of Mediating Effects}

In this study, Amos24.0 was used to analyze the mediating effect, the Bootstrap method was used for repeated sampling, and the mediating effect was tested by the methods of Bias Corrected and Percentile. The results are shown in Figure 2 and Table 5. It can be seen from Table 5 that in the direct path of resilience to career decision-making difficulties, the $\mathrm{CI}$ value of $\mathrm{a}^{*} \mathrm{~b}$ does not contain 0 , so the 
Table 3. Description of the correlation between the three variables.

\begin{tabular}{cccccc}
\hline & Mean & SD & Resilience & $\begin{array}{c}\text { Career } \\
\text { adaptability }\end{array}$ & $\begin{array}{c}\text { Career } \\
\text { decision-making } \\
\text { difficulties }\end{array}$ \\
\hline Resilience & 3.435 & 0.581 & 1 & & \\
Career adaptability & 3.741 & 0.551 & $0.742^{* *}$ & 1 & \\
Career decision-making difficulties & 2.851 & 0.623 & $-0.427^{* *}$ & $-0.450^{* *}$ & 1 \\
\hline
\end{tabular}

Note: ${ }^{* *}: p<0.01$.

Table 4. Mediating path model indicators.

\begin{tabular}{ccccccccc}
\hline CMIN & DF & CMIN/DF & RMR & GFI & AGFI & TLI & CFI & RMSEA \\
\hline \multirow{2}{*}{122.464} & 32 & 3.827 & 0.015 & 0.965 & 0.941 & 0.977 & 0.983 & 0.065 \\
\hline
\end{tabular}

Table 5. Mediating path results.

\begin{tabular}{|c|c|c|c|c|c|c|c|}
\hline & \multirow{3}{*}{ Point estimate } & \multirow{2}{*}{\multicolumn{2}{|c|}{ Product of coefficients }} & \multicolumn{4}{|c|}{ Bootstrap 5000 times $95 \% \mathrm{CI}$} \\
\hline & & & & \multicolumn{2}{|c|}{ Bias corrected } & \multicolumn{2}{|c|}{ Percentile } \\
\hline & & SE & $\mathrm{Z}$ & Lower & Upper & Lower & Upper \\
\hline RES-CDD & -0.214 & 0.076 & $\begin{array}{c}\text { Indirect effect } \\
-2.816\end{array}$ & -0.370 & -0.069 & -0.369 & -0.068 \\
\hline RES-CDD & -0.285 & 0.083 & $\begin{array}{c}\text { Direct effect } \\
-3.433\end{array}$ & -0.440 & -0.110 & -0.444 & -0.115 \\
\hline RES-CDD & -0.498 & 0.041 & $\begin{array}{c}\text { Total effect } \\
-12.146\end{array}$ & -0.579 & -0.415 & -0.581 & -0.416 \\
\hline
\end{tabular}

Note: RES = resilience; $\mathrm{CDD}=$ career decision-making difficulties.

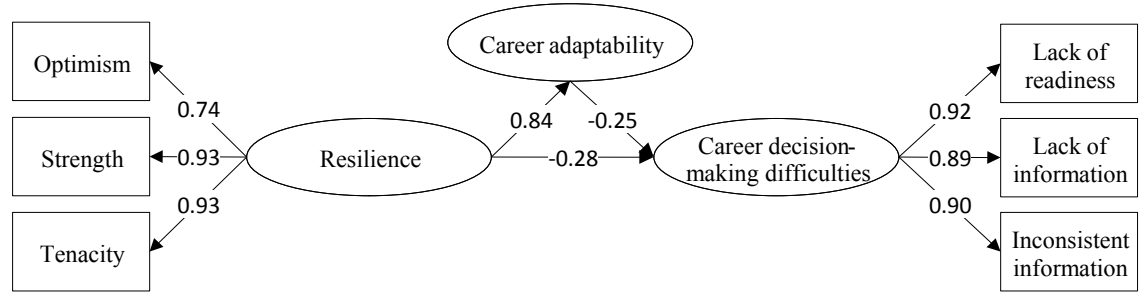

Figure 2. Mediating path diagram of career adaptability.

direct path of resilience to career decision-making difficulties is significant. The mediating effect is -0.285 . In the indirect path, the CI value of $a \times b$ does not contain 0 . Therefore, the indirect effect of resilience on career decision-making difficulties through career adaptability is established, and the indirect effect is -0.214 . Therefore, career adaptability played a partial mediating role between resilience and career decision-making difficulties. The total effect of resilience and career adaptability on career decision-making difficulties is -0.498 . Thus, Hypothesis 3 was supported.

\section{Discussion}

The goal of this research is to explore the relationship between resilience, career 
adaptability, and career decision-making difficulties. Current research has found that there is a positive correlation between resilience and career adaptability. Resilience and career decision-making difficulties are negatively correlated. Career adaptability and career decision-making difficulties are negatively correlated. Career adaptability plays a partial mediating role in resilience and career decisionmaking difficulties. Specifically, through the mediating role of career adaptability, resilience can directly or indirectly affect career decision-making difficulties. The results of this study confirm the research hypothesis put forward by this study. In addition, the findings also fill up the gaps in the existing literature on the relationship between the three variables, it also further expands the research on resilience in the career field.

As mentioned above, resilience has not yet received widespread attention from researchers in the career field. Not only that, research still lacks a systematic career theory to conduct in-depth research on resilience and career field related variables, and the role and mechanism of resilience in the process of individual career development are not clear enough. Based on the career adaptation model, this research examines the role and mechanism of resilience in the process of individual career development. The research results confirm that resilience can have a significant effect on career decision-making difficulties through personal career adaptability. Therefore, in a theoretical sense, the results of this study can well test the career adaptation model. Resilience as a personality factor can be regarded as a kind of adaptability in the career adaptation model. This adaptability helps to improve the individual's career adaptation level and then helps the individual to prepare for career choices. At the same time, it can also help individuals reduce the difficulty of information exploration in the career decision-making process and the conflicts in the decision-making process.

In previous studies, there has not been a clear understanding of the relationship between resilience and career adaptability. Studies have pointed out that the level of individual career adaptability can positively predict resilience (Ginevra et al., 2017; Santilli et al., 2020; Xu et al., 2020). Different from this result, some studies believe that an individual's resilience level can positively predict career adaptability. For example, (Abukhait et al., 2020) found that a resilient employee may be better able to cope with adverse and stressful situations and more easily adapt to changing circumstances. The results of this study are the same as the latter. The study shows that the resilience of Chinese college students can significantly positively predict the level of career adaptability. Specifically, resilience is an enduring characteristic of an individual. With the passage of time and the growth of life experience and age, they can respond to the environment (Roberts, 2018). It is worth noting that resilient people are not characterized by unconditional positive emotions, but by their ability to switch emotional responses flexibly to match the needs of these experiences, which brings them a new light (Waugh et al., 2011). Therefore, there is a positive relationship between high levels of resilience and the ability to adapt to change (Waugh et al., 2011). 
This study shows that resilience and career adaptability as positive factors can effectively reduce the level of individual career decision-making difficulties. It is not difficult to imagine that, from the practical perspective of life, if an individual is more resilient in pursuing future goals and can maintain an optimistic and open mind to face difficulties, then the individual can also actively think about career development and be more self-conscious. The curiosity and exploration of career opportunities and the self-efficacy of solving career-related problems are high. Therefore, these positive factors may help make more positive cognitive judgments about their lives and enable them to quickly recover from difficulties.

The results of this study have certain practical significance. Affected by the post-epidemic era, students are facing a complex and severe employment situation. As positive factors, resilience and career adaptability play an important role in the student's career decision-making process. Therefore, schools should attach importance to and cultivate students' resilience and career adaptability. First of all, schools should carry out various activities to help students develop resilience and career adaptability. For example, a group tutoring project is carried out on campus to provide targeted tutoring to students with low resilience and career adaptability, and to help students improve their ability to deal with setbacks and challenges through training. It is also possible to hold a career planning competition to arouse students' awareness of their future careers. Students can further understand their own strengths and weaknesses in the competition, understand the ability requirements of future careers, and know how to match themselves with their careers, so as to prepare for job hunting. Secondly, schools should pay attention to and innovate the curriculum arrangements for college students' careers. For example, some challenging activities can be set up in the course to exercise students' resilience. In addition, students can also conduct simulation practice, and raise students' attention to career development through occupational interviews, collect employment information and industry information about future jobs. In the career course study, students can get an open and optimistic attitude towards career development, so as to respond to career decisions in the best state.

\section{Conclusion}

Resilience has a direct or indirect negative predictive effect on career decisionmaking self-efficacy. This study further illustrates how resilience plays a role. More importantly, the results of this study confirm the importance of resilience to students' career decision-making. Individuals with high levels of resilience have relatively high career adaptability, which plays a vital role in helping students make career decisions. According to the results of this study, educators and career counselors can better understand the relationship between resilience, career adaptability, and career decision-making difficulties. In addition, educators and career counselors can also design various career interventions to help students develop resilience and career adaptability. 


\section{Acknowledgements}

The authors would like to thank the reviewers for their valuable comments on the manuscript.

\section{Funding}

This research was funded by Jiangsu Province University's Advantageous Discipline Construction Project, grant number "PAPD".

\section{Conflicts of Interest}

The authors declare no conflicts of interest regarding the publication of this paper.

\section{References}

Abukhait, R., Bani-Melhem, S., \& Shamsudin, F. M. (2020). Do Employee Resilience, Focus on Opportunity, and Work-Related Curiosity Predict Innovative Work Behavior? The Mediating Role of Career Adaptability. International Journal of Innovation Management, 24, Article ID: 2050070. https://doi.org/10.1142/S136391962050070X

Bimrose, J., \& Hearne, L. (2012). Resilience and Career Adaptability: Qualitative Studies of Adult Career Counseling. Journal of Vocational Behavior, 81, 338-344.

https://doi.org/10.1016/j.jvb.2012.08.002

Chui, H., Li, H., \& Ngo, H. (2020). Linking Protean Career Orientation with Career Optimism: Career Adaptability and Career Decision Self-Efficacy as Mediators. Journal of Career Development, Article ID: 089484532091252. https://doi.org/10.1177\%2F0894845320912526

Connor, K. M., \& Davidson, J. R. T. (2003). Development of a New Resilience Scale: The Connor-Davidson Resilience Scale (CD-RISC). Depression and Anxiety, 18, 76-82. https://doi.org/10.1002/da.10113

Di Fabio, A., Palazzeschi, L., \& Bar-On, R. (2012). The Role of Personality Traits, Core Self-Evaluation, and Emotional Intelligence in Career Decision-Making Difficulties. Journal of Employment Counseling, 49, 118-129. https://doi.org/10.1002/j.2161-1920.2012.00012.x

Di Fabio, A., Palazzeschi, L., Levin, N., \& Gati, I. (2014). The Role of Personality in the Career Decision-Making Difficulties of Italian Young Adults. Journal of Career Assessment, 23, 281-293. https://doi.org/10.1177\%2F1069072714535031

Gati, I., Krausz, M., \& Osipow, S. H. (1996). A Taxonomy of Difficulties in Career Decision Making. Journal of Counseling Psychology, 43, 510-526.

https://doi.apa.org/doi/10.1037/0022-0167.43.4.510

Gati, I., Osipow, S. H., Krausz, M., \& Saka, N. (2000). Validity of the Career Decision-Making Difficulties Questionnaire: Counselee versus Career Counselor Perceptions. Journal of Vocational Behavior, 56, 99-113. https://doi.org/10.1006/jvbe.1999.1710

Ginevra, M. C., Di Maggio, I., Santilli, S., Sgaramella, T. M., Nota, L., \& Soresi, S. (2017). Career Adaptability, Resilience, and Life Satisfaction: A Mediational Analysis in a Sample of Parents of Children with Mild Intellectual Disability. Journal of Intellectual \& Developmental Disability, 43, 473-482. https://doi.org/10.3109/13668250.2017.1293236 
Hirschi, A., Herrmann, A., \& Keller, A. C. (2015). Career Adaptivity, Adaptability, and Adapting: A Conceptual and Empirical Investigation. Journal of Vocational Behavior, 87, 1-10. https://doi.org/10.1016/j.jvb.2014.11.008

Hou, Z.-J., Leung, S. A., Li, X., Li, X., \& Xu, H. (2012). Career Adapt-Abilities Scale-China Form: Construction and Initial Validation. Journal of Vocational Behavior, 80, 686-691. https://doi.org/10.1016/j.jvb.2012.01.006

Jia, Y., Hou, Z. J., Zhang, H., \& Xiao, Y. (2020). Future Time Perspective, Career Adaptability, Anxiety, and Career Decision-Making Difficulty: Exploring Mediations and Moderations. Journal of Career Development, No. 5, Article ID: 089484532094192. https://doi.org/10.1177\%2F0894845320941922

Karacan-Ozdemir, N. (2019). Associations between Career Adaptability and Career Decision-Making Difficulties among Turkish High School Students. International Journal for Educational and Vocational Guidance, 19, 475-495. https://doi.org/10.1007/s10775-019-09389-0

Levin, N., Braunstein-Bercovitz, H., Lipshits-Braziler, Y., Gati, I., \& Rossier, J. (2019). Testing the Structure of the Career Decision-Making Difficulties Questionnaire across Country, Gender, Age, and Decision Status. Journal of Vocational Behavior, 116, Article ID: 103365. https://doi.org/10.1016/j.jvb.2019.103365

Maggiori, C., Rossier, J., \& Savickas, M. L. (2015). Career Adapt-Abilities Scale-Short Form (CAAS-SF): Construction and Validation. Journal of Career Assessment, 25, 312-325. https://doi.org/10.1177\%2F1069072714565856

Maree, J. G. K. (2017). Opinion Piece: Using Career Counselling to Address Work-Related Challenges by Promoting Career Resilience, Career Adaptability, and Employability. South African Journal of Education, 37, 1-5. https://doi.org/10.15700/saje.v37n4opinionpiece

Maree, J. G., \& Pollard, Z. (2009). The Impact of Life Design Counselling on Adolescents. Journal of Psychology in Africa, 19, 169-175. https://doi.org/10.1080/14330237.2009.10820276

Maree, J. G., \& Symington, C. (2015). Life Design Counselling Effects on the Career Adaptability of Learners in a Selective Independent School Setting. Journal of Psychology in Africa, 25, 143-150. https://doi.org/10.1080/14330237.2015.1021531

Parmentier, M., Pirsoul, T., \& Nils, F. (2021). Career Adaptability Profiles and Their Relations with Emotional and Decision-Making Correlates among Belgian Undergraduate Students. Journal of Career Development, 1-17. https://doi.org/10.1177\%2F08948453211005553

Roberts, B. W. (2018). A Revised Sociogenomic Model of Personality Traits. Journal of Personality, 86, 23-35. https://doi.org/10.1111/jopy.12323

Rudolph, C. W., Lavigne, K. N., \& Zacher, H. (2017). Career Adaptability: A Meta-Analysis of Relationships with Measures of Adaptivity, Adapting Responses, and Adaptation Results. Journal of Vocational Behavior, 98, 17-34. https://doi.org/10.1016/j.jvb.2016.09.002

Santilli, S., Grossen, S., \& Nota, L. (2020). Career Adaptability, Resilience, and Life Satisfaction among Italian and Belgian Middle School Students. The Career Development Quarterly, 68, 194-207. https://doi.org/10.1002/cdq.12231

Savickas, M. L. (1997). Career Adaptability: An Integrative Construct for Life-Span, Life-Space Theory. Career Development Quarterly, 45, 247-259. https://doi.org/10.1002/j.2161-0045.1997.tb00469.x

Savickas, M. L. (2005). The Theory and Practice of Career Construction. In R. W. Lent, \& S. D. Brown (Eds.), Career Development and Counseling: Putting Theory and Research 
to Work (pp. 42-70). Hoboken, NJ: John Wiley \& Sons.

Savickas, M. L., \& Porfeli, E. J. (2012). Career Adapt-Abilities Scale: Construction, Reliability, and Measurement Equivalence across 13 Countries. Journal of Vocational Behavior, 80, 661-673. https://doi.org/10.1016/j.jvb.2012.01.011

Savickas, M. L., Nota, L., Rossier, J., Dauwalder, J. P., Duarte, M. E., Guichard, J. et al. (2009). Life Designing: A Paradigm for Career Construction in the 21st Century. Journal of Vocational Behavior, 75, 239-250. https://doi.org/10.1016/j.jvb.2009.04.004

Savickas, M. L., Porfeli, E. J., Hilton, T. L., \& Savickas, S. (2018). The Student Career Construction Inventory. Journal of Vocational Behavior, 106, 138-152. https://doi.org/10.1016/j.jvb.2018.01.009

Semmer, N. (2006). Personality, Stress, and Coping. In M. E. Vollrath (Eds.), Handbook of Personality and Health (pp. 73-113). Chichester: John Wiley \& Sons. https://doi.org/10.1002/9780470713860.ch4

Shin, Y.-J., \& Kelly, K. R. (2015). Resilience and Decision-Making Strategies as Predictors of Career Decision Difficulties. The Career Development Quarterly, 63, 291-305. https://doi.org/10.1002/cdq.12029

Super, D. E., \& Knasel, E. G. (1981). Career Development In adulthood: Some Theoretical Problems and a Possible Solution. British Journal of Guidance and Counselling, 9, 194-201. https://doi.org/10.1080/03069888108258214

Tien, H.-L. S. (2005). The Validation of the Career Decision-Making Difficulties Scale in a Chinese Culture. Journal of Career Assessment, 13, 114-127. https://doi.org/10.1177\%2F1069072704270327

Tugade, M. M., \& Fredrickson, B. L. (2004). Resilient Individuals Use Positive Emotions to Bounce Back from Negative Emotional Experiences. Journal of Personality and Social Psychology, 86, 320-333. https://doi.apa.org/doi/10.1037/0022-3514.86.2.320

Wagnild, G. M., \& Young, H. M. (1993). Development and Psychometric Evaluation of the Resilience Scale. Journal of Nursing Measurement, 1, 165-78.

Waugh, C. E., Thompson, R. J., \& Gotlib, I. H. (2011). Flexible Emotional Responsiveness in Trait Resilience. Emotion, 11, 1059-1067. https://doi.apa.org/doi/10.1037/a0021786

Wehmeyer, M. L., Nota, L., Soresi, S., Shogren, K. A., Morningstar, M. E., Ferrari, L. et al. (2018). A Crisis in Career Development: Life Designing and Implications for Transition. Career Development and Transition for Exceptional Individuals, 42, 179-187. https://doi.org/10.1177\%2F2165143417750092

Xu, C., Gong, X., Fu, W., Xu, Y., Xu, H., Chen, W., \& Li, M. (2020). The Role of Career Adaptability and Resilience in Mental Health Problems in Chinese Adolescents. Children and Youth Services Review, 112, Article ID: 104893. https://doi.org/10.1016/j.childyouth.2020.104893

Yu, X., Zhang, J., Yu, X. N., \& Zhang, J. X. (2007). Factor Analysis and Psychometric Evaluation of the Connor-Davidson Resilience Scale (CD-RISC) with Chinese People. Social Behavior \& Personality: An International Journal, 35, 19-30. https://doi.org/10.2224/sbp.2007.35.1.19

Zhou, D., \& Santos, A. (2007). Career Decision-Making Difficulties of British and Chinese International University Students. British Journal of Guidance \& Counselling, 35, 219-235. https://doi.org/10.1080/03069880701256684 